\title{
Design of Ultra Low Power 7.2 GHz True Single Phase Clock CMOS 2/3 Prescaler244 $\mu \mathrm{W}$
}

\author{
Roshan Kumar' ${ }^{1}$, Prof. Monika Kapoor ${ }^{2}$ \\ PG Student, VLSI Design, LNCT Bhopal ${ }^{1}$ \\ ECE Department, LNCT Bhopal, MP, India ${ }^{2}$
}

\begin{abstract}
In this paper a high operating frequency and power efficient TSPC prescaler layout is proposed and compared with the existing TSPC and E-TSPC prescalers on the basis of operating frequency and power consumption. The maximum operating frequency of the proposedTSPC prescaler is $7.2 \mathrm{GHz}$ which is $10 \%$ higher than other TSPC based prescalers and 7\% than E-TSPC based prescalers with average power consumption of $307 \mu \mathrm{W}$ at $1.8 \mathrm{~V}$ supply voltage. This High Frequency is achieved by reducing propagation delay in PMOS and NMOS at different stages. The power consumption in divide by 2 and divide by 3 mode is $3 \%$ to $10 \%$ better than all other prescalers and four times better than those prescalers which can be operated higher than $6.5 \mathrm{GHz}$ frequency.This prescaler consumes $348 \mu \mathrm{W}$ in divide by 2 mode and $244 \mu \mathrm{W}$ in divide by 3 mode.
\end{abstract}

Keywords: Dual modulus prescaler, D Flip-flop (DFF), True single phase clock (TSPC), Microwind, DSCH, Frequency synthesizer, Clock, Propagation Delay.

\section{INTRODUCTION}

True Single phase Clock Dual modulus prescaler is an essential part of frequency synthesizer which generates variable frequency by using only one clock signal. Frequency synthesizersare digital circuits used to generate variable frequency which plays a major role in digital devices where multiple and/or variable clock frequency are required. Frequency synthesizersuses different techniques such as frequency divider, frequency multiplier and direct digital synthesizer. A high speed dual modulus prescaler frequency synthesizersis used in many electronic systems such as timing recovery circuit,clock generator etc. In a frequency synthesizer, prescaler consumes maximum power with respect to other components. By reducing the power consumption of prescaler it is possible to make a power efficient frequency synthesizer. A dual modulus prescaler uses a wideband swallow frequency divider and has $\mathrm{N}$ and $\mathrm{N}+1$ division ratios. Frequency synthesizer produces variable frequency by using prescaler and control circuit. This control unit uses two counters, Programmable Counter (P) and Swallow Counter (S), it is shown in Fig. 1. The combination of Prescaler and counters $\mathrm{P}$ and $\mathrm{S}$ performs $\mathrm{N} \times \mathrm{P}+\mathrm{S}$ programmable division ratio.

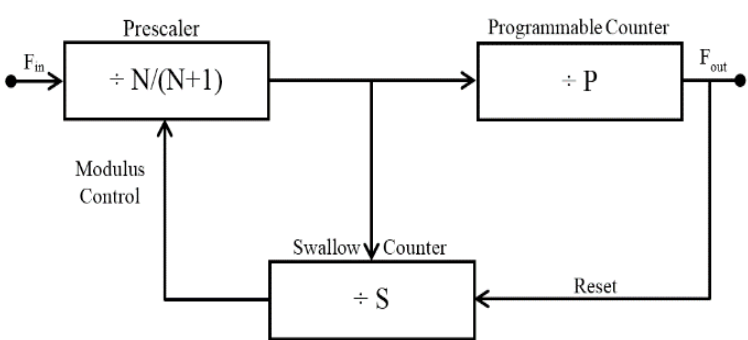

Fig. 1. Topology of the Pulse Swallow frequency divider
Dynamic latch frequency synthesizer, injection locked frequency dividers (ILFDs) and source-coupled logic (SCL) [7], [8] are three are widely used techniques for making high speed flip-flops for prescaler. Basically prescaler are made of D flop-flop and logic gates. Those D flop-flopscan be driven by single phase clock [3], [5] or multiple phase clock. Those logic gates are used between D flop-flops to generate two consecutive divisional ratios. In the prescaler the $\mathrm{D}$ flip-flops are controlled directly by clock signal so the speed of the circuit is dependent on the speed of logic gates and switching power also increases.

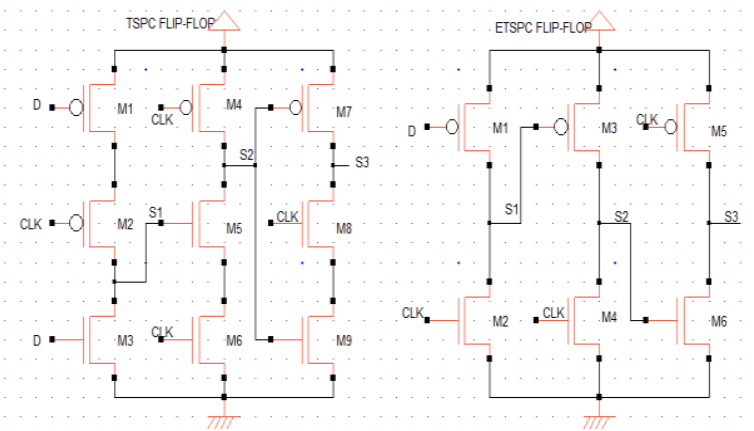

Fig. 2. TSPC and E-TSPC flip-flop.

The CMOS N/ $(\mathrm{N}+1)$ current mode logic (CML) [7] based prescaler can be operated as high as $24 \mathrm{GHz}$ [6]. But the major drawback of the prescaler is the large load capacitances which increases power consumption. On the other hand the injection locked frequency dividers (ILFDs) have very small locking range and it also required large chip area for injection locking circuit. While Dynamic CMOS needs very small chip area with low power needs. 


\section{ANALYSIS OF TSPC ANDE-TSPC FLIP-FLOP}

In this section TSPC [3], [9], and E-TSPC [10] based flipflops are analysed with its power consumption and frequency response.In dynamic latch frequency synthesiser, multiple phase clock frequency synthesiser are better for compact circuits and these are more power efficient than single phase frequency synthesizer. The maximum operating frequency is also higher. But these are not good for complex and big circuits because these generally prone to the clock skewing problem. It is difficult to maintain equal electrical length of all the clocks signals in same phase difference through tracks to each component in entire device. That's why single phase clock frequency synthesiser are widely used for big and complex circuit.

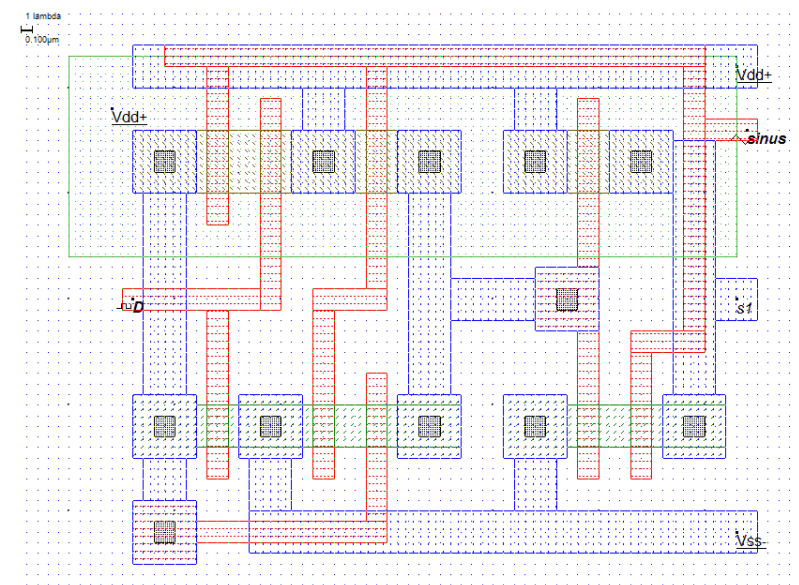

Fig. 3 (a) TSPCflip-flop Layout.

The TSPC and E-TSPC flip-flop both have three stages to generate output from input. The TSPC flip-flop acquires three Transistors in each stage while E-TSPC flip-flop needs only two as in Fig. 2. The calculation of load capacitances is done by connecting output $(\mathrm{Q})$ of both the flip-flops to their corresponding inputs (D). The load capacitance of TSPC and E-TSPC according to method [11] and [12] is given by

$$
\begin{aligned}
& \mathrm{C}_{\mathrm{L}_{\mathrm{TSPC}}}=\mathrm{C}_{\mathrm{DB}_{\mathrm{M} 8}}+2 \mathrm{C}_{\mathrm{GD}_{\mathrm{M} 8}}+\mathrm{C}_{\mathrm{DB}_{\mathrm{M} 7}}+2 \mathrm{C}_{\mathrm{GD}_{\mathrm{M}} 7}+\mathrm{C}_{\mathrm{G}_{\mathrm{M}}} \\
& +\mathrm{C}_{\mathrm{G}_{\mathrm{M} 1}} \\
& \mathrm{C}_{\mathrm{L}_{\mathrm{E}-\mathrm{TSPC}}}=\mathrm{C}_{\mathrm{DB}_{\mathrm{M}} 6}+2 \mathrm{C}_{\mathrm{GD}_{\mathrm{M}} 6}+\mathrm{C}_{\mathrm{DB}_{\mathrm{M} 5}}+2 \mathrm{C}_{\mathrm{GD}_{\mathrm{M} 5}}+\mathrm{C}_{\mathrm{G}_{\mathrm{M} 1}}
\end{aligned}
$$

Equations shows that, TSPC flip-flop has higher load capacitance than E-TSPC flip-flop. The TSPC flip-flop consumes more power than E-TSPC at switching which is dependent on load capacitance is given by

$$
\mathrm{P}_{\text {switching }}=\mathrm{f}_{\text {clk }} \mathrm{C}_{\mathrm{L}} \mathrm{V}_{\mathrm{dd}}^{2}
$$

Though the TSPC has higher switching power but ideally there is on direct path between supply voltage and ground during operation. As the transistors are not identical and PMOS and NMOS are not reciprocal as long as electrical properties are concerned, some power is consumed, it is called short circuit power. It also depends on rise and fall time of the input signals and clocks. The short circuit power [13] is directly proportional to the load capacitance.
Since there is one direct pathexists between each consecutive stages at the time of transition between supply voltage and ground in E-TSPC flip-flop. So that it consumes significantly more short circuit current than TSPC flip-flop. The short circuit power also dependent on the time for which a transistor is in floating state (neither high nor low) which increases with increasing frequency. Which again shows that in E-TSPC short circuit power increases with increases in clock frequency.

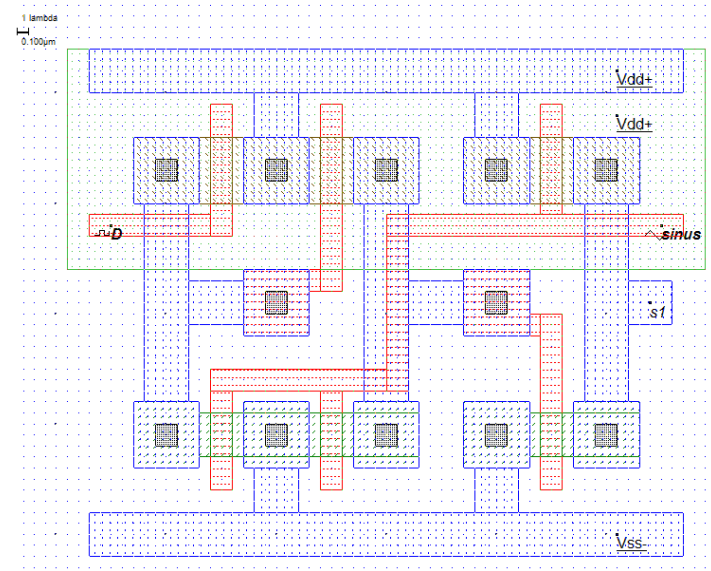

Fig. 3 (b) E-TSPC flip-flop Layout.

The circuit analysis is done by Microwind using $180 \mathrm{~nm}$ technologyat 1.8 Volts $\mathrm{V}_{\mathrm{dd}}$. Layout of both TSPC flip-flop and E-TSPC flip-flop shown in Fig. 3 (a)and Fig. 3 (b) are designed simulated with deferent DC levels and variable amplitudes at same $4 \mathrm{GHz}$ frequency to find out dependency of circuits on output of VCO and also to analyse the power consumption. In simulation both circuits are tested on DC levels from 0.7 to 1.2 volts, and for each DC level, clock amplitude is also varied from $400 \mathrm{mV}$ to $700 \mathrm{mV}$. The input is a $1 \mathrm{GHz}$ signal with $50 \mathrm{ps}$ of rise time and fall time.

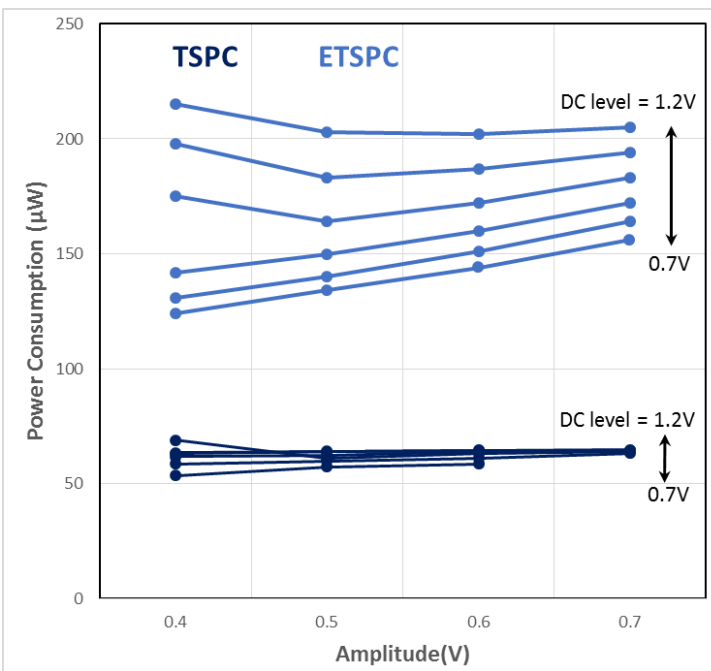

Fig. 4. Power consumption against different DC levels and amplitude of clock signal for TSPC and E-TSPC flip-flop. 
The simulation shows the power consumption of TSPC flip-flop varies from 50 to $65 \mu \mathrm{W}$ for entire range of tested DC level and Amplitudes. On the other hand ETSPC flipflop consumed more power from 120 to $215 \mu \mathrm{W}$ which is not only more than double but also varies significantly with DC levels and Amplitudes. It is also observed that the output waveforms of TSPC flip-flop is quiet identical in all simulation but the wave forms of ETSPC flip-flop simulation are deferent in shape Thesimulation results in Fig. 4 shows that the TSPC flip-flop is better than ETSPC flip-flop.

\section{ANALYSIS OF PROPOSED TSPC PRESCALER}

In the $2 / 3$ prescaler proposed in [1] shown in Fig. 5, the two NOR gates are implanted in to the flip-flops. This helped to reduce total number of transistors used to implement each NOR gate, as depicted in Fig. 6.The first NOR gate is embedded in to first D flip-flop using only one NMOS transistor M10 at the output node S3 in the third stage of flip-flop. This node S3 is connected to the second NOR gate which is embedded in to the first stage of second D flip-flop. This implementation reduced the additional stages introduced by an extra invertor used to invert the output of DFF1 and the digital gates between both the $\mathrm{D}$ flip-flops of the conventional TSPC 2/3 prescaler. This elimination reduced the total number of switching nodes from 12 to 7, and less number of nodes also reduced the switching power $\mathrm{P}_{\text {switching _[1] }}$ of prescaler, it is given by

$$
\mathrm{P}_{\text {switching _[1] }}=\sum_{\mathrm{j}=1}^{7} \mathrm{f}_{\mathrm{clk}} \mathrm{C}_{\mathrm{Lj}} \mathrm{V}_{\mathrm{dd}}^{2}
$$

The total capacitance $C_{L_{-}[1]}$ of $2 / 3$ prescaler of [1] at the output node $\mathrm{Q}$ is given by

$$
\begin{aligned}
\mathrm{C}_{\mathrm{L}_{-}[1]}=\mathrm{C}_{\mathrm{DB}_{\mathrm{M} 19}}+ & \mathrm{C}_{\mathrm{DB}_{\mathrm{M} 20}} \\
& +2\left(\mathrm{C}_{\mathrm{GD}_{\mathrm{M} 19}}+\mathrm{C}_{\mathrm{GD}_{\mathrm{M} 20}}\right)+\mathrm{C}_{\mathrm{G}_{\mathrm{M} 11}} \\
& +\mathrm{C}_{\mathrm{G}_{\mathrm{M} 15}}+\mathrm{C}_{\mathrm{G}_{\mathrm{M} 22}}+\mathrm{C}_{\mathrm{G}_{\mathrm{M} 23}}
\end{aligned}
$$

The total load capacitance $\mathrm{C}_{\mathrm{L}}$ at the output node $\mathrm{Q}$ of Conventional TSPC $2 / 3$ prescaler is given by

$$
\begin{aligned}
\mathrm{C}_{\mathrm{L}}=\mathrm{C}_{\mathrm{DB}_{\mathrm{M} 30}}+ & \mathrm{C}_{\mathrm{DB}_{\mathrm{M} 31}}+2\left(\mathrm{C}_{\mathrm{GD}_{\mathrm{M} 30}}+\mathrm{C}_{\mathrm{GD}_{\mathrm{M} 31}}\right)+\mathrm{C}_{\mathrm{G}_{\mathrm{M} 1}} \\
& +\mathrm{C}_{\mathrm{G}_{\mathrm{M} 3}}+\mathrm{C}_{\mathrm{G}_{\mathrm{M} 19}}+\mathrm{C}_{\mathrm{G}_{\mathrm{M} 20}}+\mathrm{C}_{\mathrm{G}_{\mathrm{M} 33}} \\
& +\mathrm{C}_{\mathrm{G}_{\mathrm{M} 34}}
\end{aligned}
$$

And total switching power $\mathrm{P}_{\text {switching }}$ of all 12 stages of Conventional $2 / 3$ prescaler is given by

$$
\mathrm{P}_{\text {switching }}=\sum_{\mathrm{i}=1}^{12} \mathrm{f}_{\text {clk }} \mathrm{C}_{\mathrm{Li}} \mathrm{V}_{\mathrm{dd}}^{2}
$$

By comparing the load capacitances of both conventional $2 / 3$ prescaler and [1] 2/3 prescaler the load capacitance of [1] based $2 / 3$ prescaler is significantly less at the output node Q. It resulted less propagation delay and low power consumption.In this analysis, both the conventional TSPC $2 / 3$ prescaler and [1]2/3 prescaler are designed with having constant width of $3 \mu \mathrm{m}$ for the PMOS and constant width of $2 \mu \mathrm{m}$ for the NMOStransistors. The reduction of switching power in the [1] $2 / 3$ prescaler compared to the conventional TSPC $2 / 3$ prescaler is given by

$$
\mathrm{P}_{\text {switching_saved }}=\sum_{\mathrm{i}=1}^{12} \mathrm{f}_{\mathrm{clk}} \mathrm{C}_{\mathrm{Li}} \mathrm{V}_{\mathrm{dd}}^{2}-\sum_{\mathrm{j}=1}^{7} \mathrm{f}_{\mathrm{clk}} \mathrm{C}_{\mathrm{Lj}} \mathrm{V}_{\mathrm{dd}}^{2}
$$

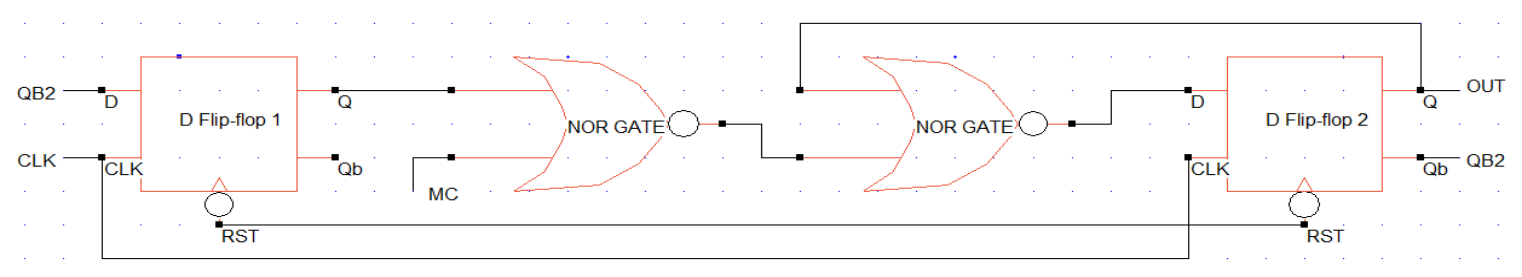

Fig. 5. TSPC $2 / 3$ prescaler circuit proposed in [1].

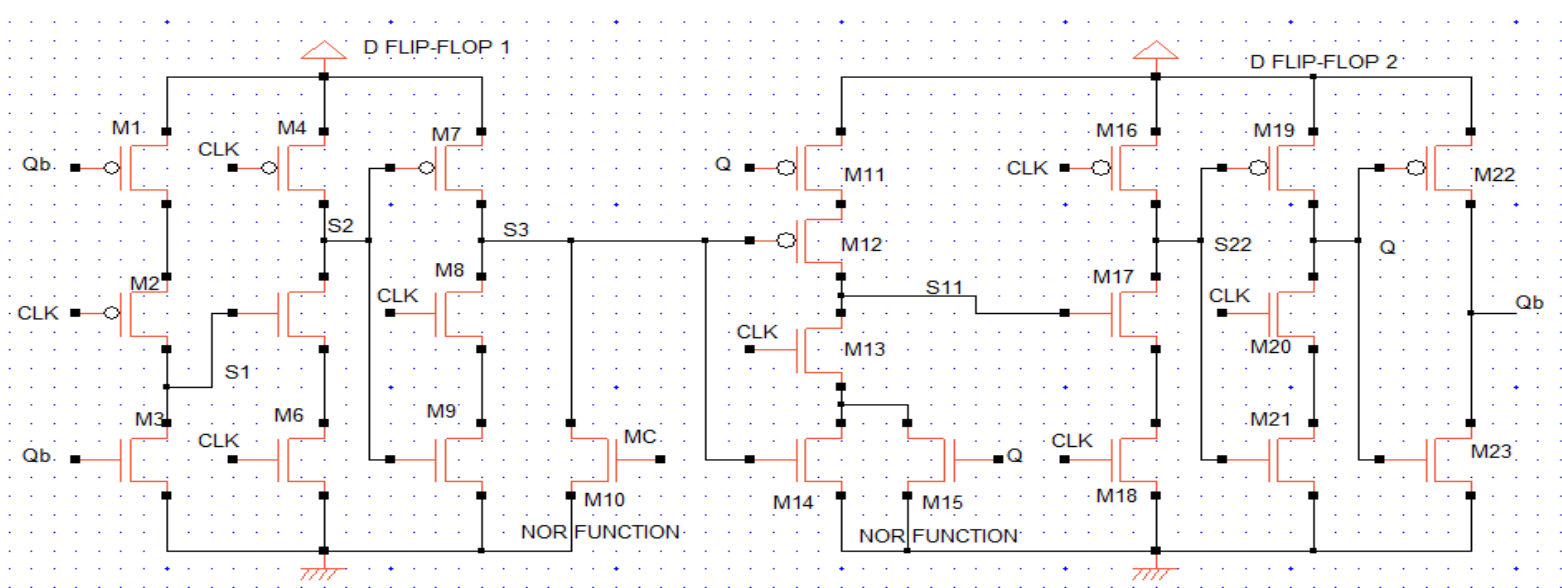

Fig. 6. TSPC $2 / 3$ prescaler gate level schematic diagram proposed in [1]. 
In the proposed $2 / 3$ prescaler the width of NMOS and higher operating frequency which are verified by PMOS transistor is not taken constant. Different widths for simulation results. each transistor is chosen to equalise the mobility of cascade transistors in both pull-up and pull-down networks which are driven by same input signal. It helped to reduce propagation delay difference between NMOS and PMOS of every stage driven by same input signal. This prescaler is almost three times power efficient and supports 58\% higher operating frequency compared to that of the conventionalTSPC 2/3 prescaler, And comparing with the [1] prescaler, it is $10 \%$ power efficient and supports $25 \%$
In the proposed $2 / 3$ prescaler the width of all NMOS is $600 \mathrm{nmexcept}$ M15. The width of M15 is $800 \mathrm{~nm}$ which is used to drive positive cycle of the feedback properly. The width of the PMOS used to implement D flip-flop and Invertor is taken between $1000 \mathrm{~nm}$ to $1100 \mathrm{nmbut}$ for PMOS M11 and M12 it is taken 600nm to make a little delay while feed-back cycle is low. This helped the circuit to significantly reduce power consumption in divide by 2 mode.Layout of Proposed 2/3 prescaler is shown in Fig. 7.

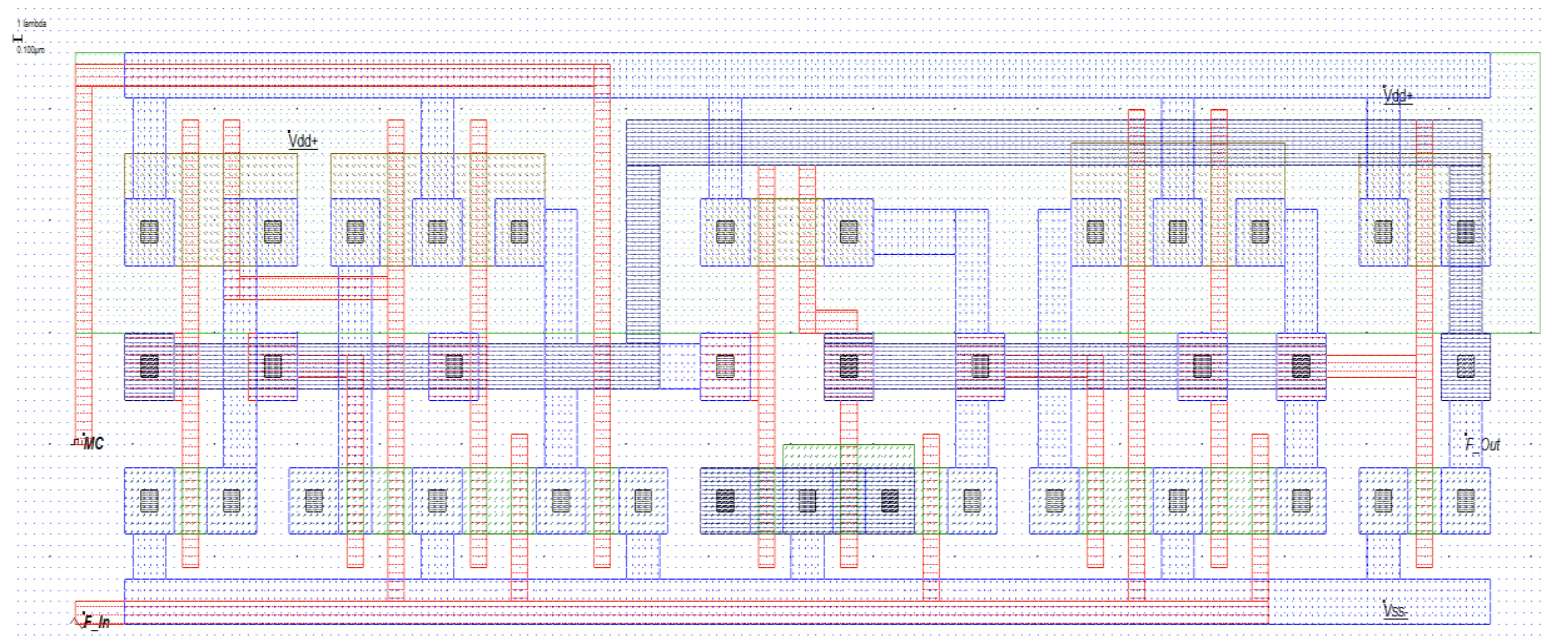

Fig. 7. Proposed Layout of TSPC $2 / 3$ Prescaler.

\section{SIMULATION AND MEASURMENT RESULTS}

Microwind 3.5 and DSCH 3.5 software are used to perform all the simulations with $180 \mathrm{~nm}$ CMOS Technology. All simulations are done by taking all parameters constant accept supply voltage. The supply voltageis $1.5 \mathrm{~V}$ for [14] and [15] prescalers and for other prescalers supply voltage is $1.8 \mathrm{~V}$. From the simulation the [1] is most power efficient with $5.5 \mathrm{GHz}$ operating frequency. While [2] can be operated up to $6.5 \mathrm{GHz}$ which is highest for a TSPC based prescaler. In the simulation of proposed circuit an input sinusoidal signal of $7.2 \mathrm{GHz}$ is applied as clock input on F_In with $0.9 \mathrm{~V}$ DC level is and $0.9 \mathrm{~V}$ peak to peak amplitude. Sinusoidal input signal is taken for simulation because on chip available VCO generates sinusoidal signal. And the Module Control input is feed with a $100 \mathrm{MHz}$ clock signal with 50 ps rise time and fall time to observe response in divide by 2 and divide by 3 mode and the output is taken from F_Out.

The frequency response shown in Fig 9 shows that the circuit generates very stable output. In divide by 3 mode the output measured is $2.4 \mathrm{GHz}$ and in divide by 2 mode the output measured is $3.6 \mathrm{GHz}$ which is strictly proportional to the input clock frequency $7.2 \mathrm{GHz}$. The time taken to produce stable output is less than $2 \mathrm{~ns}$ for both divide by 2 and divide by 3 mode. The average power consumption of the prescaler is $307 \mu \mathrm{W}$ shown in Fig 9 . The power consumptionin divide by 2 mode and divide by 3 mode are $348 \mu \mathrm{W}$ and $244 \mu \mathrm{W}$ respectively. The maximum operating frequency and power consumption of proposed prescaler is compared with different Prescalers, it is shown Fig. 8 and in Table 1.1.

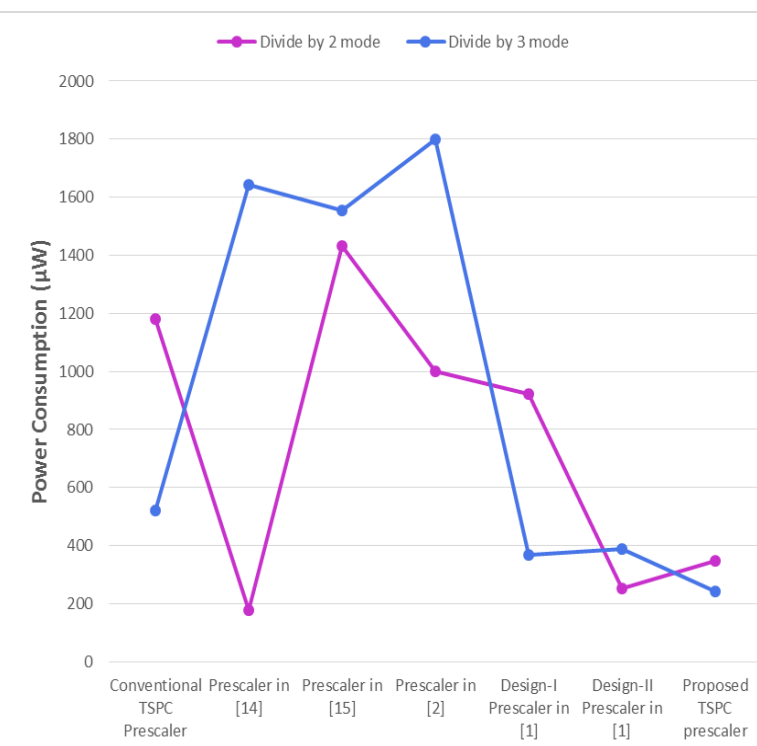

Fig. 8. Performance of different prescalers 


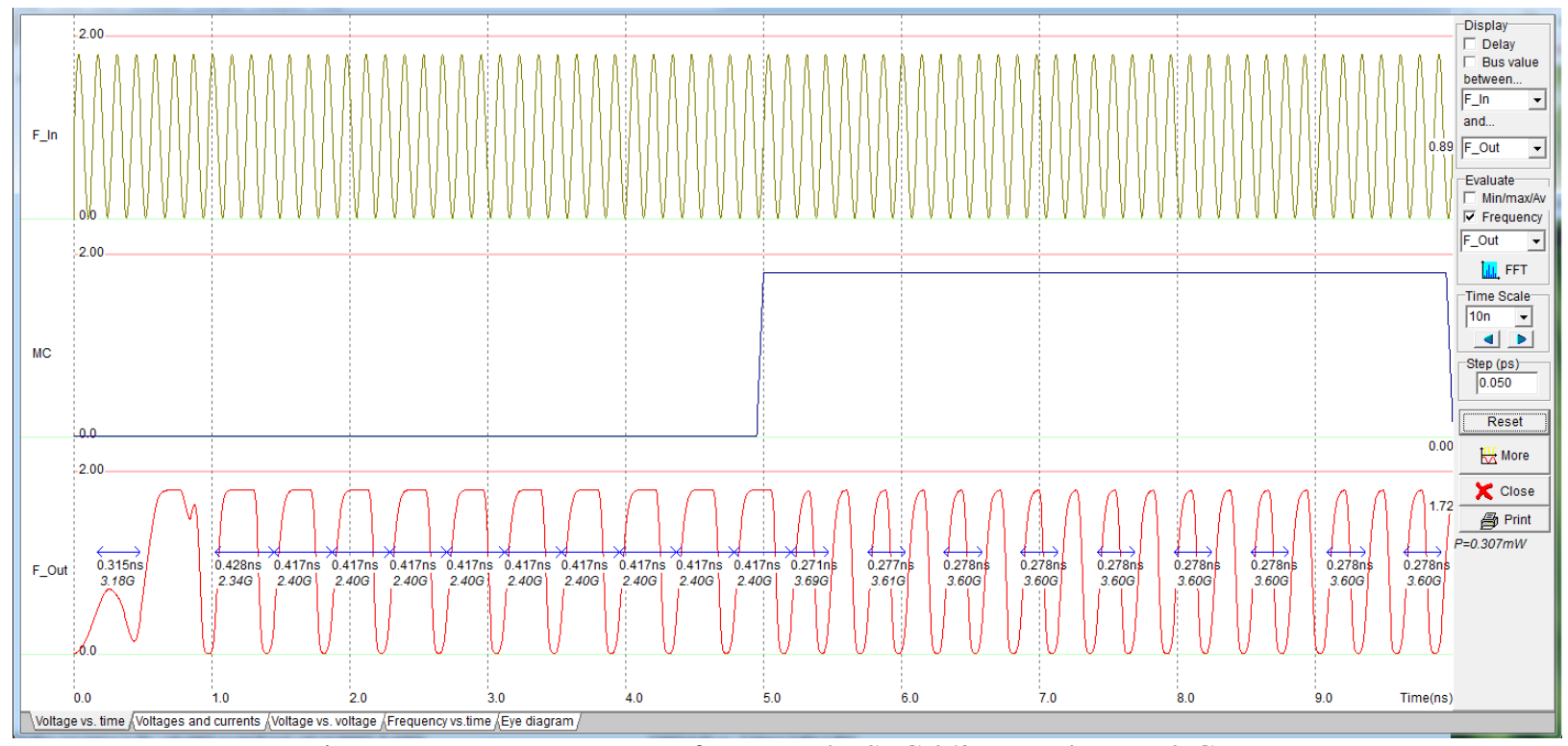

Fig. 9. Frequency response of Proposed TSPC $2 / 3$ prescaler at $7.2 \mathrm{GHz}$.

Table 1. Maximum Operating Frequency and Power consumption comparison among different Prescalers

\begin{tabular}{|c|c|c|c|c|c|c|c|}
\hline $\begin{array}{c}\text { Design } \\
\text { Parameters }\end{array}$ & $\begin{array}{c}\text { Conventio } \\
\text { nal TSPC } \\
\text { Prescaler }\end{array}$ & $\begin{array}{c}\text { Prescaler } \\
\text { in [14] }\end{array}$ & $\begin{array}{c}\text { Prescaler } \\
\text { in [15] }\end{array}$ & $\begin{array}{c}\text { Prescaler } \\
\text { in [2] }\end{array}$ & $\begin{array}{c}\text { Design-I } \\
\text { Prescaler } \\
\text { in [1] }\end{array}$ & $\begin{array}{c}\text { Design-II } \\
\text { Prescaler } \\
\text { in [1] }\end{array}$ & $\begin{array}{c}\text { Proposed } \\
\text { TSPC } \\
\text { Prescaler }\end{array}$ \\
\hline Process (nm) & 180 & 180 & 180 & 180 & 180 & 180 & 180 \\
\hline $\begin{array}{c}\text { Supply Voltage } \\
(\mathrm{V})\end{array}$ & 1.8 & 1.5 & 1.5 & 1.8 & 1.8 & 1.8 & 1.8 \\
\hline $\begin{array}{c}\text { Maximum } \\
\text { Frequency } \\
(\mathrm{GHz})\end{array}$ & 4.2 & 5.5 & 6.7 & 6.5 & 5.5 & 5.5 & $\mathbf{7 . 2}$ \\
\hline $\begin{array}{c}\text { Power } \\
\text { consumption } \\
(\mu \mathrm{W} \text { ) Divide-by-2 } \\
\text { mode }\end{array}$ & 1182 & 178 & 1433 & 1000 & 923 & 252 & $\mathbf{3 4 8}$ \\
\hline $\begin{array}{c}\text { Power } \\
\text { consumption( } \mu \mathrm{W}) \\
\text { Divide-by-3 mode }\end{array}$ & 522 & 1643 & 1554 & 1800 & 369 & 387 & $\mathbf{2 4 4}$ \\
\hline
\end{tabular}

\section{CONCLUSION}

In this paper a high frequency $2 / 3$ prescaler is proposed which can operate up to $7.2 \mathrm{GHz}$ which is $30 \%$ higher than the prescalers proposed in base paper, $10 \%$ higher than all other TSPC prescalers and 7\% higher than ETSPC based prescalers. The software used for all simulation is Microwind 3.5 with $180 \mathrm{~nm}$ technology at supply voltage $1.8 \mathrm{~V}$. This proposed prescaler is not only supports high frequency but also consumes least power than all other TSPC and E-TSPC prescalers in both divide by 2 mode and divide by 3 mode. In divide by 2 mode it consumes $348 \mu \mathrm{W}, 2.5$ times less than design I of [1] and in divide by 3 mode it consumes $244 \mu \mathrm{W}$ which is $50 \%$ less than [1]. This prescaler also consumes four times less power than those prescalers which can be operated 6.5 $\mathrm{GHz}$ or higher frequency. This circuit is suitable low power frequency synthesiser with high frequency response.
According to the observation the maximum operating frequency can further be increased.

\section{REFERENCES}

[1] M. V. Krishna, M. A. Do, K. S. Yeo, W. M. Lim and C. C. Boon, "Design and Analysis of Ultra Low Power True Single Phase Clock CMOS 2/3 Prescaler," in IEEE Transaction on Circuits and Systems, vol. 57, pp. 72-82, Jan. 2010.

[2] M. V. Krishna, M. A. Do, K. S. Yeo, C. C. Boon and W. M. Lim, "A 1.8-V 6.5-GHz low power wide band single-phase clock CMOS $2 / 3$ prescaler," in IEEE Int. Symp. on Circuits and Systems, vol. 53, pp. 149-152, Aug. 2010.

[3] Y. Ji-ren, I. Karlsson, and C. Svensson, "A true single-phase-clock dynamic CMOS circuit technique,” IEEE J. Solid-State Circuits, vol. 24, pp. 62-70, Feb. 1989.

[4] Q. Huang and R. Rogenmoser, "Speed optimization of edge triggered CMOS circuits for gigahertz single-phase clocks," IEEE J. SolidState Circuits, vol. 31, pp. 456-465, Mar. 1996.

[5] C.-Y. Yang, G.-K. Dehng, J.-M. Hsu, and S.-I. Liu, "New dynamic flip-flops for high-speed dual-modulus prescaler," IEEE J. Solidstate Circuits, vol. 33, pp. 1568-1571, Oct. 1998. 
[6] H.-D.Wohlmuth and D. Kehrer, "A $24 \mathrm{GHz}$ dual-modulus prescaler in $90 \mathrm{~nm}$ CMOS," in IEEE Int. Symp. on Circuits and Systems, May 2005, vol. 4, pp. 3227-3230.

[7] C. M. Hung, B. A. Floyd, N. Park, and O. Kenneth, "Fully integrated $5.35 \mathrm{GHz}$ CMOS VCO and prescalers," IEEE Transactions on Microwave Theory and Techniques, vol. 49, no. 1, pp. 17-22, Jan. .

[8] M. Alioto and G. Palumbo, "Design strategies for source coupled logic gates," IEEE Trans. Circuits and Syst. I: Reg. Papers, vol. 50, no. 5, pp. 640-654, May 2003.

[9] J. Yuan and C. Svensson, "High-Speed CMOS circuit technique," IEEE J. Solid-State Circuits, vol. 24, pp. 62-70, Feb. 1989

[10] J. Navarro and W. Van Noije, "E-TSPC: Extended true single-phase clock CMOS circuit technique," in Proc. Int. Conf. on Integrated Syst. on Silicon IFIP and VLSI, London, U.K., 1997, pp. 165-176.

[11] J. M. Rabaey, A. Chandrakasan, and B. Nikolic, Digital Integrated Circuits, A Design Perspective, ser. Electron and VLSI, 2nd ed. Upper Saddle River, NJ: Prentice-Hall, 2003.

[12] S.-M. Kang and Y. Leblebici, CMOS Digital Integrated Circuits, Analysis and Design, 3rd edition New York: McGraw Hill, 2002.

[13] H. J. M. Veendrick, "Short-circuit dissipation of static CMOS circuitry and its impact on the design of buffer circuits," IEEE J. Solid-State Circuits, vol. SC-19, no. 4, Aug. 1984.

[14] S. Pellerano, S. Levantino, C. Samori, and A. L. Lacaita, "A 13.5$\mathrm{mW} 5 \mathrm{GHz}$ frequency synthesizer with dynamic-logic frequency divider," IEEE J. Solid-State Circuits, vol. 39, no. 2, pp. 378-383, Feb. 2004.

[15] X. P. Yu, M. A. Do, W. M. Lim, K. S. Yeo, and J. G. Ma, "Design and optimization of the extended true single-phase clock-based prescaler," IEEE Trans. Microw. Theory Tech., vol. 54, no. 11, Nov. 2006.

[16] J. Yuan and C. Svensson, "New single-clock CMOS latches and flip-flops with improved speed and power savings," IEEE J. Solidstate Circuits, vol. 32, no. 1, pp. 62-69, Jan. 1997. 